\title{
Redescription of Melanagromyza sojae (Zehntner) from India and Nepal
}

\author{
Ram Bahadur Thapa \\ Department of Zoology, Post Graduate Campus, T.U. Biratnagar, Nepal \\ E-mail:niwaj@yahoo.com
}

\begin{abstract}
Six new species of other stem flies infesting mostly legumes were also discovered under the genus Melanagromyza (stem flies) from Pantnagar, Northern India. These were: $M$. species new ex stems of Cassia sp. (proposed name M. pathaki new species); $M$. species new ex stems of Glycine max (Linn.) Merril. (proposed name M. glycini new species); $M$. species new ex stems of Medicago denticulata willd. (proposed name $M$. denticulata Willd. new species); $M$. species new ex stems of Pisum sativum Linn. (proposed name M. pisiphaga new species); $M$. species new ex stems of Trifolium pratense Linn,. (proposed name $M$. sehgali new species) and $M$. species new ex stems of Vicia faba Linn. (proposed name M. vicivora new species). New names have been proposed to them as per International rules of Zoological Nomenclature. Other stem flies redescribed by author include: Ophiomyia centrosematis de Meijere, Opmiormyia phaseoli (Tryon) and Ophiomyia cicerivora. More than one thousand male genitalia slides were prepared for this study. Variations in morphology and genitalia characters have been described between and within the species. Melanagromyza sojae (Zehtner) has been redescribed here.
\end{abstract}

Key words: Leaf miners, stem fly, Diptera, Cyclorraphous, Agromyzidae

\section{Introduction}

Species of the genus Melanagromyza belong to Cyclorraphous (Diptera) of the family Agromyzidae. They are internal plant feeders. Almost 75 percent of them are leaf miners and remaining one fourth feed inside the parts of plant, like stem miners, pod feeders and seed feeders. In the world, 83 species of leaf miners are feeding on leguminous host plants. Thapa (1991) has added 13 new species of legume feeders belonging to Agromyzidae from India. World record shows that there are more than 2000 species of leaf miners infesting cultivated as well as wild host plants.

Melanagromyza sojae, the stem borer in soybean and other cultivated legumes is gaining national importance due to heavy economic losses they inflict on their host plants. During the study, redescription of Melanagomyza sojae was done with illustrations of genitalia. Morphological and genitalic variations within this species has also been studied by Thapa (1991).

Thapa $(1997,2000)$ has reared this species from Vigna radiata (Linn.) Wilczek from Biratnagar, eastern Nepal. Poudyal (2003) has reared M. sojae from Glycine max (Linn.) Merr., Pisum sativum Linn. and Vigna mungo Linn. from Jhapa district, eastern Nepal. 
Thapa (2005) during her study on Mung bean variety K85, produced and marketed by sunseed (India) Cooperation, Haryana India, determined 6 species of flies. She could rear 3 species of stem flies like: Melanagromyza sojae, M. hibisci Spencer, and Ophiomyia centrosenatis (de Meijere). The various species were found infesting various stages of plants and the infestation was found to reach up to $100 \%$. New host plants were also recorded.

Thapa $(1991,1997,2000)$ has studied other stem flies mining stems of various host plants. These include Ophiomyia centrosematis de Meijere, Ophiomyia phaseoli (Tryon) and Ophiomyia cicerivora. These flies were also redescribed and illustrated. Melanagromyza hibisci Spencer and M. cleomae have been also reared from various host plants (Thapa, 2097, 2000; Thapa, 2005).

\section{Materials and Methods}

The research was carried out at Govinda Ballabh Pant University of Agriculture and Technology, Pantnagar (Nainital), as well as at Biratnagar and Jhapa, eastern Nepal. The general concept used in this study has been adopted from Sasakawa (1960, 1961), Spencer (1973), Singh and Ipe (1973), Sehgal et al. (1980) and Spencer and Stayskal (1986).

An attempt was made to study all the existing species which could be reared during the survey. Apart from describing a new species, detailed morphological variations and differences in genetalia characters among the members within the species were also carefully evaluated and illustrated wherever felt necessary. Besides describing morphological and gentalia characters, their biology and host plants were also studied.

In addition to re-describing 15 known species, induding $M$. sojae (Zehntner), 13 species were described and new names have been proposed for them as per International rules of Zoological Nomendature. Melanagromyza sojae is redescribed here.

\section{Results and Discussion}

The redescription of Melanogromyza sojae was done as follows: Melanagromyza sojae (Zehntner); Agromyza sojae Zehntner (1900); Agromyza prolifica (Malloch, 1914); Agromyza producta (Malloch, 1914; Singh \& Ipe, 1973); Agromyza squamata (Becker, 1903); Melanagromyza sojae (Zehntner) (de Meijere 1922; Sasakawa, 1961; Singh \& Ipe, 1973; Thapa, 1991).

Comparison- The members of this species do not differ much in external morphology with those of a similar species Melanagromyza vicivora new species exstems of Vicia faba Linn (Thapa, 1991). However, characters of genitalia in sojae (Zehntner) are distinctive in having prominent loop, bladder do not curves much and extends beyond rear of Mesophallus. Morphological characters alone are not sufficient to distinguish the members of this species with those of other related species of this region. However, the distinctive characters of genitalia readily segregate them. The members of sojze (Zehntner) from same or different leguminous host-plants had remarkable differences in colouration and genitalia characters like relations of bladder and mesophallus (Pl. 1, Fig. 5; Pl. 6, Fig. 6) or lobes of basal part of distiphallus narrow (Pl. 7, Fig. 5) or broader (Pl. 5, Fig. 5; Pl. 7, Fig. 5; Pl. 8, Fig. 4) or coiled (Pl. 7, Fig. 5). Shape, size and position of bladder (Pl. 8, Fig. 4) remarkably varied among the members. 
Another, closely related species of $M$. sojae (Zehntner) is $M$. cunctans (Meigen) known only from Southern and Western Europe, where it forms stem galls on Lotus corniculatus L. The two species can not be distinguished either by external characters or male genitalia but differ in biology (Spencer, 1973). Distinctive genitalia of sojae has been illustrated by Kato (1961), Sasakawa (1960) and Spencer (1973) and Thapa (1991).
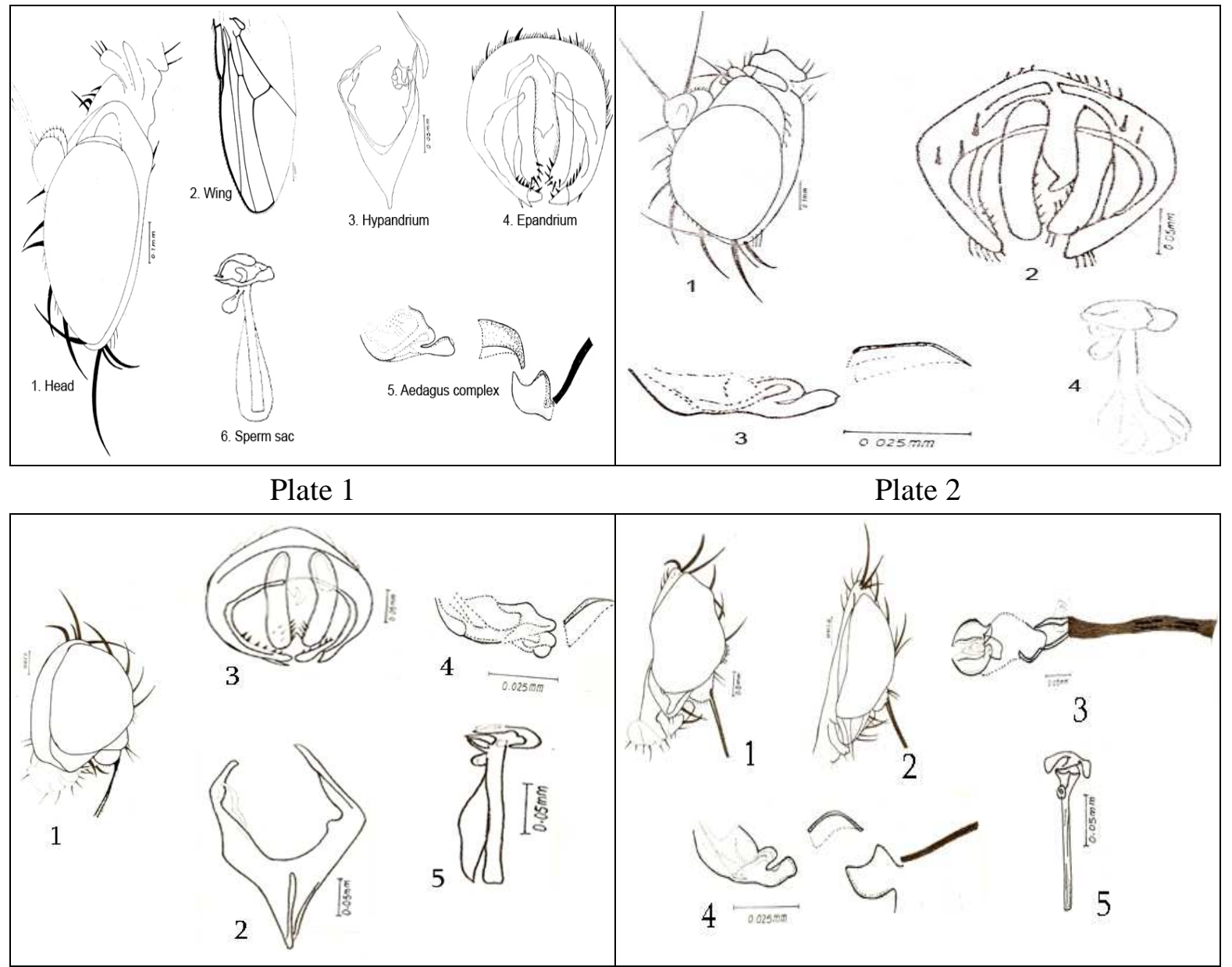

\section{Plate 3}

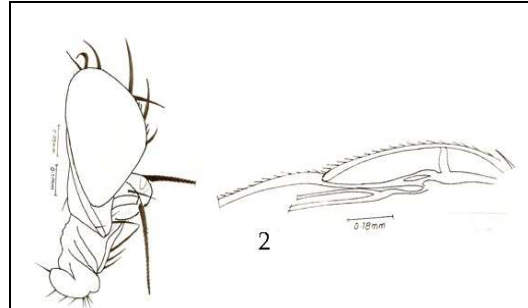

1

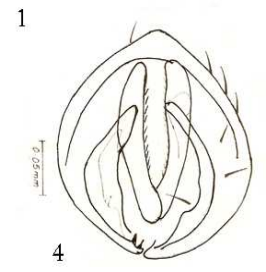

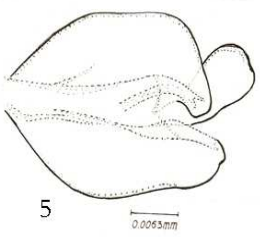

Plate 5
Plate 4

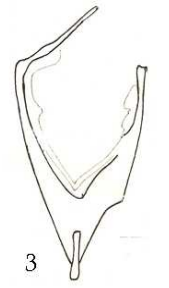

1
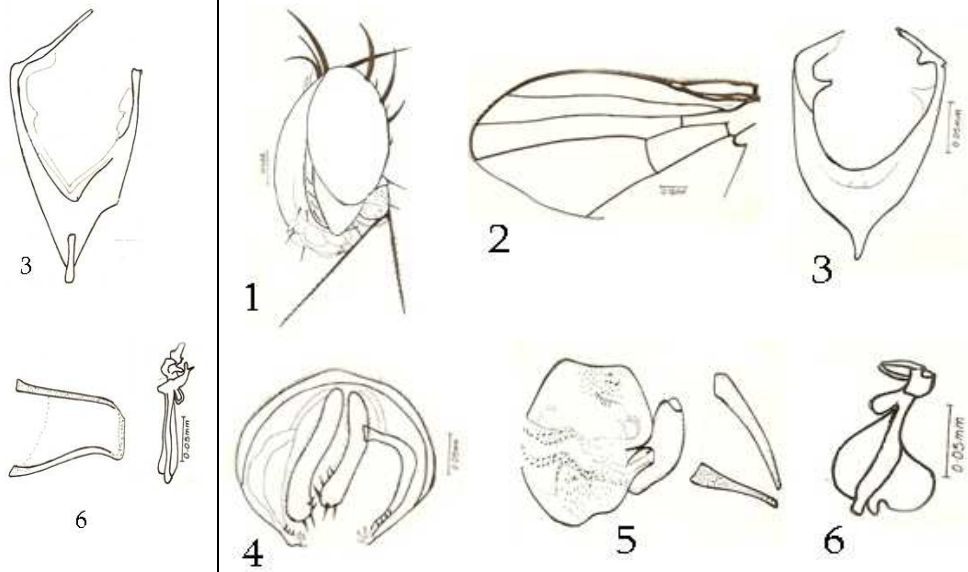
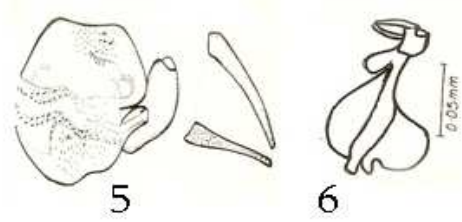

Plate 6 


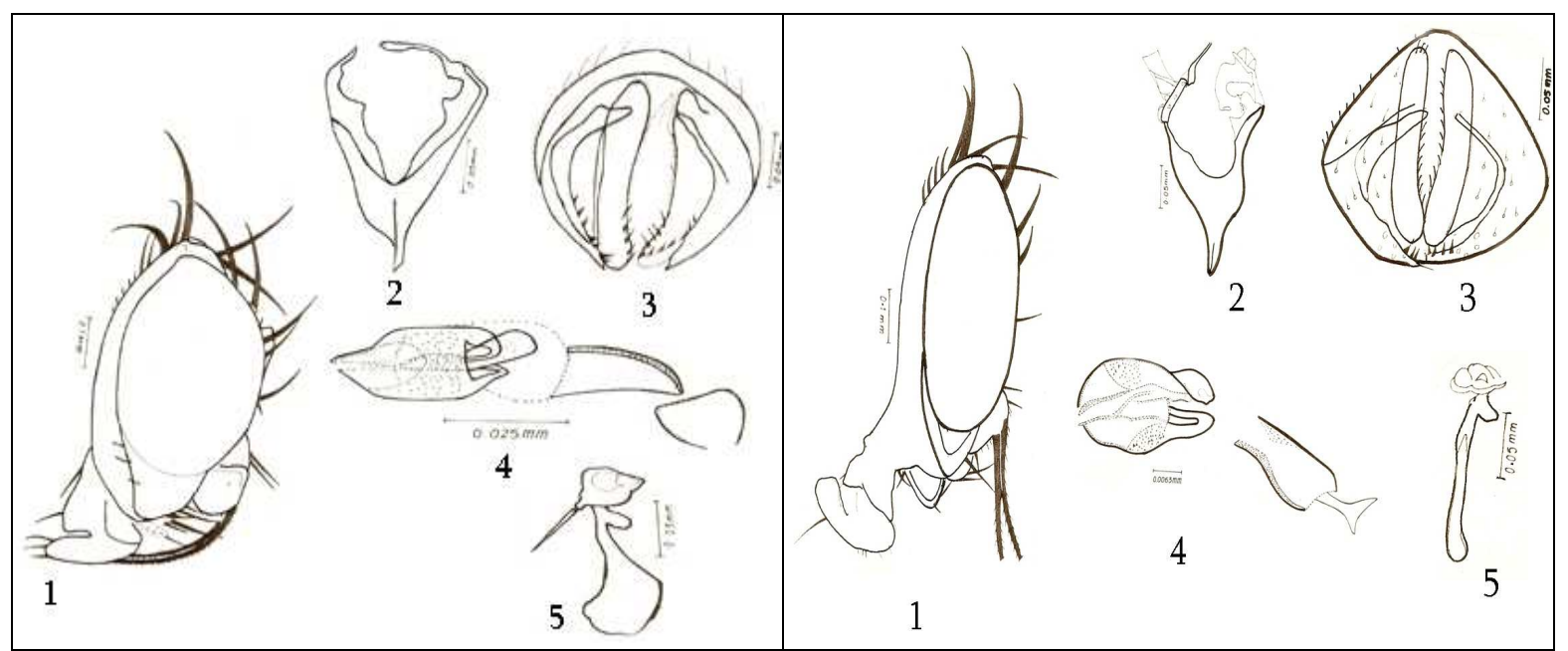

Plate 7

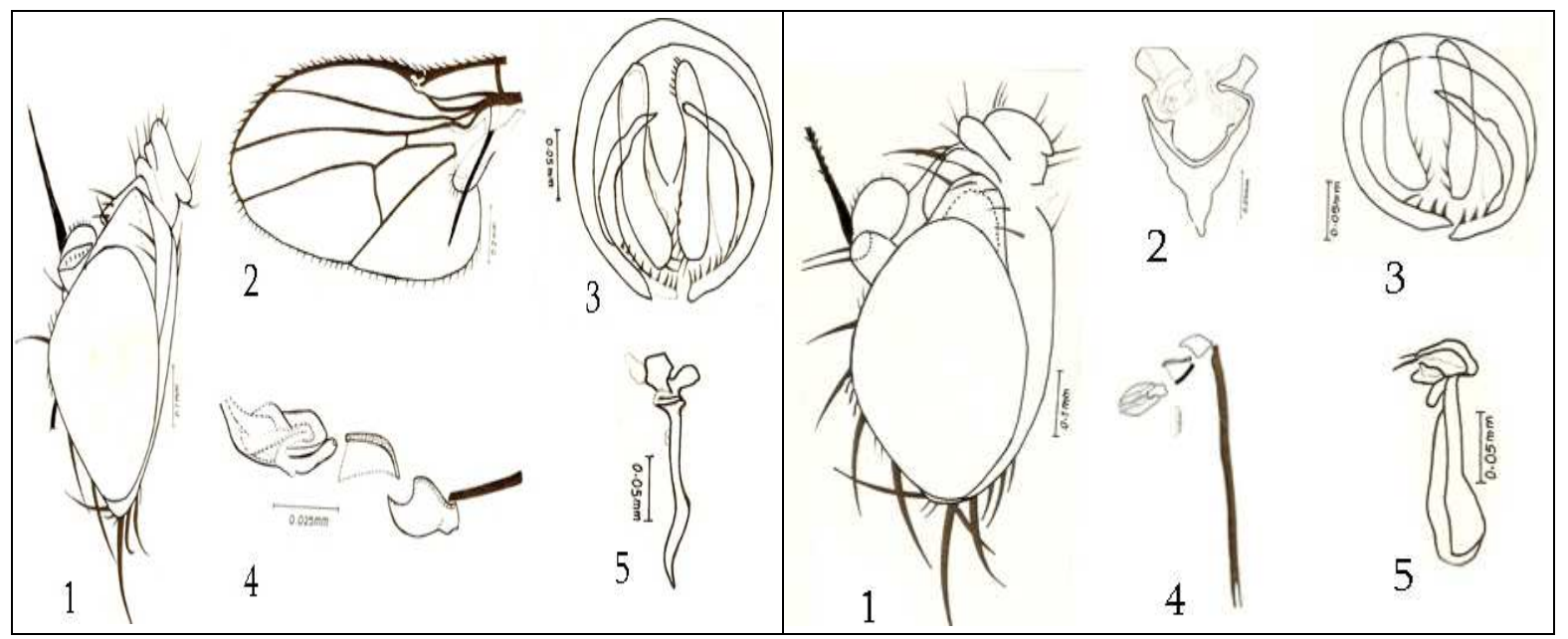

Plate 9

Plate 10

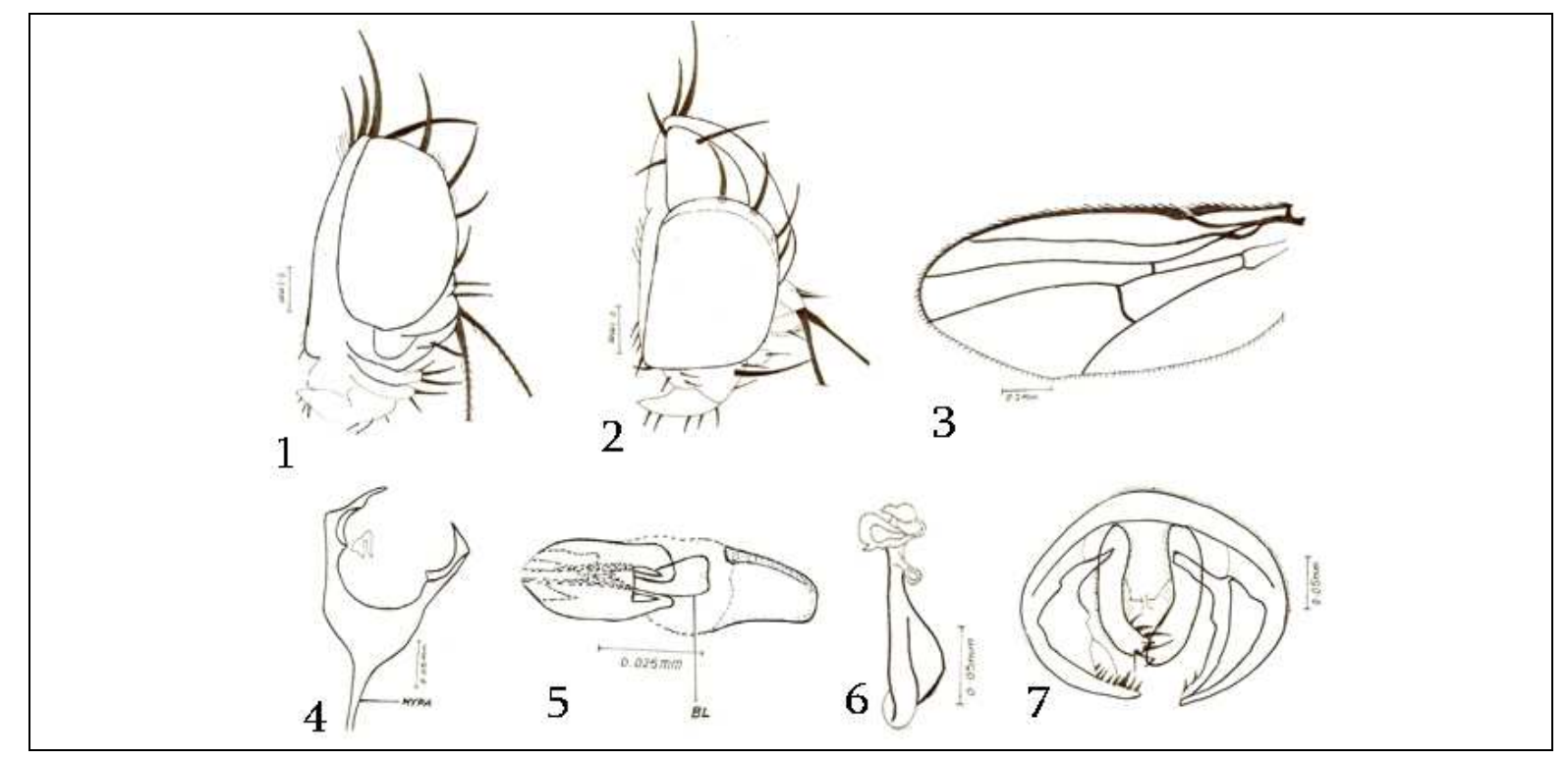

Plate 11 
Diagnostic characters: The members of this species are small, with black mesonotum and green abdomen, wing length $1.68-2.26 \mathrm{~mm}$ in males; third and $4^{\text {th }}$ costal segments are unequal; gena 1/4-1/7.66 vertical height of eye; arista slightly pubescent to bare; squammae witish to brownish, margin and fringes white; halters black or greyish. However, typical sojae (Pl. 2, Fig. 1) is characterized by frons slightly wider (1.16 times) than the width of eye; eyes 1.91 times higher than their lengths; gena 1/7.6 vertical height of eye; wing length $1.97 \mathrm{~mm}$ in male, arista virtually bare; frons and orbit not projected in profile.

Description: Head (Pl. 1, Fig. 1): Width of frons 0.105-0.294mm, 0.66-1.6 times wider than the eye at the level of front median ocellus, slightly projected or not projected beyond eye in profile; ori 2-3, unequal directed slightly upwards or strong, directed upwards; orbital setulae sparse to numerus, reclinate, apart from 1 or 2 hairs infront proclinate; eyes oval, bare; lunule broad and semi circular antennal bases approximate, in 6 specimens widely separated, fascial keel absent, narrow fascial keel present in 6 specimens, vibrissae numerous; eyes 0.399-0.525 mm, 1.3-2.2 times higher than their lengths; gena 0.063-0.105 $\mathrm{mm}, 1 / 4-1 / 7.66$ vertical height of eye; ocellar triangle small, ocellar bristles strong; orbits normal, raised from the plane of frons, not projected in front of eye margin in profile; third antennal article round with an angle, pubescence normal, arista long slightly pubescent to virtually bare. Mesootum: Two strong dc; acr numerous. Wing (Pl. 1, Fig. 2). Length 1.68$2.26 \mathrm{~mm}$ in males; subcosta joining $\mathrm{R}_{1}$; costa extended to $\mathrm{M}_{1+2}$; costal segments $2-4$ in the ratio 1:0.25: 0.17-1:0.32:0.22; cross vein $\mathrm{m}-\mathrm{m}$ present; distal section of $\mathrm{M}_{3+4}$ 0.44-0.86 times basal portion. Male genitalia: Hypandrium (Pl. 1, Fig. 3) Y shape with long and broad side arms in few specimens U shaped (Pl. 6, Fig. 3) with short side arms, apodeme varies from short, narrow (Pl. 4, Fig. 5) to long and broad (Plate 2, Fig 4); epandrium (Pl. 1, Fig. 4) cerci long and broad with bristles, surstyli with spines; aedeagus (Pl. 5, Fig. 5) basiphallus widely separated from distiphallus complex; ventral bladder is characteristically assymmetrical. On the basis of characters of genitalia, the specimens with one lobe narrow and another borad are treated here as typical sojae (Pl. 2) and the rest (Pls. 1, 3, 4, 5, 6, 7, 8, 9, 10, 11) are treated as variants of sojae. Aedeagus may be assymetrical or symmetrical. Colour: Frons black, in few specimens greyish; orbits black, in few specimens greyish, ocellar triangle black; lunule black, in few specimens greyish, antennae black, covered with white pubescence; mesonotum black; scutellum black; halters in most specimens black, but greyish in 14 specimens or brownish in 4 specimens or pale in 1 specimen; legs black; squammae white but brownish in 25 specimens; margin and fringes white, in few specimens margin with reddish tinge.

Biology: The larvae of this species feed inside stem of various host-plants. Pupation also occurs inside the stems. The members of sojae have been reared from various legume hostplants: Aeschynomene americana; A. indica; Cyamopsis psoralioides; Glycine max; Lathyrus pratense; Medicago denticulata; Medicago lupulina; Melilotus alba; Melilotus indica; Pisum sativum; Sesbania aculeata; Trifolium alexandrium; T. repens; Trigonella corniculata; Trigonella foenum-graecum, Vigna mungo; V. radiata; V. sinensis and $V$. umbellata during the months of October, November, December, January, March and April. More flies were reared during the months of Oct-November. Maximum number of $\delta$ flies were reared from Glycine max and Pisum sativum. It is interesting to note that only few adult $\hat{\sigma}$ of this species could be reared from Vigna mungo and $V$. radiata. 
Sehgal (1965) has reared this species from the stems of Glycine max; Melilotus sp.; Vigna mungo and V. radiata at Pantnagar, Delhi (soybean) and Ludhiana (Melilotus), during the rainy season crops. In the northern India, its biology has also been discussed by Bhattacharya and Rathore (1977) on soybean, and Singh and Beri (1973) on Vigna spp. (=Phaselous spp.) who also described the immature stages. Singh and Ipe (1977) has listed Phaseolus mungo and P. radiatus as leguminous hosts of this species. Singh (1982) has described the immature stages of this species. He has also listed Dolichos biflorus, Cajanus indicus, Glycine max, G. soja, Indigofera suffruticosa, Melilotus sp., Phaseolus calcaratus, $P$. sublobatus, $P$. radiates, $P$. mungo, Pisum sp., $P$. sativum and Vigna catjang as leguminous hosts of this species. Kato (1961) had also described the adults and immature stages of this species from japan. Spencer (1973) has listed Cajanus, Indigofera, Phaseolus swainsonia and Medicago as hosts of sojae. Vander Goot (1930) recorded Aeschynomene, Flemingia and Phaseolus as wild legume hosts in java. Sasakawa (1960) had also studied the biology of this species on Glycine soja Sieb and Zucc (Sehgal, 1965).

Geographical distribution: The member of this species are known from Africa, Australia, Asia, India, Nepal, China and Japan materials were also examined by Thapa (1997-2000), Poudyal (2003) and Thapa (2005) from Biratnagar and Jhapa, estern Nepal.

Following materials from Pantnagar, Nainital, India were examined in the present study: One $\delta$ from stem of Aeschynomene americana, Coll. 29.x.87, emerged 31.x.87; 2 $\widehat{\delta}$ from stem of Aeschynomene indica, coll. 21. xi.87, emerged 25-29.xi.87; $1 \sigma^{\lambda}$ from stem of

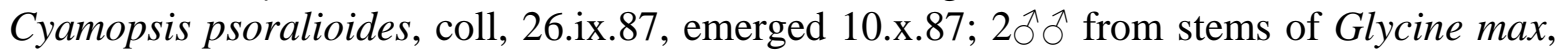

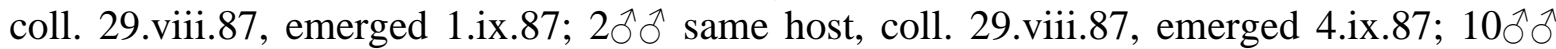

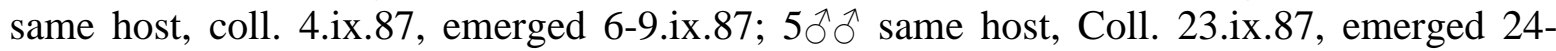

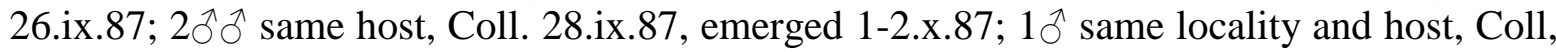
2.x.87, emerged 5.x.87; $1 \sigma^{\Uparrow}$ same host, Coll. 2.x.87, emerged 6.x.87; $1 \overbrace{}^{\Uparrow}$ same host, Coll. 2.x.87, emerged 7.x.87; $1 \delta^{\Uparrow}$ same host, Coll. 2.x.87, emerged 17.x.87; $1 \delta^{\Uparrow}$ same host, Coll.

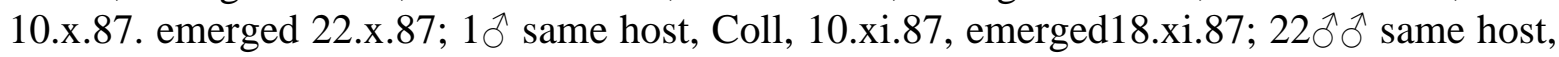

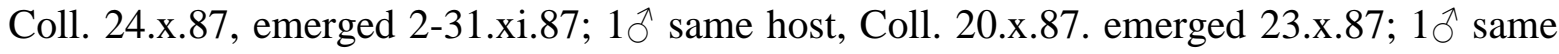
host, coll. 26.xii.87, emerged 15.i.88; $10^{\Uparrow}$ from stem of Lathyrus pratense, Cool. 20.xi.87, emerged 28.xi.87; $1 \delta^{\Uparrow}$ same host, Coll 1.iv.88, emerged 4.iv.88; $1 \sigma^{\lambda}$ from stem of Medicago

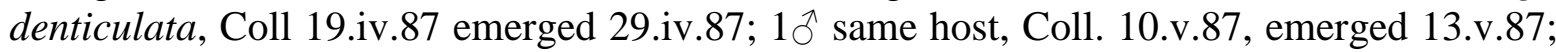

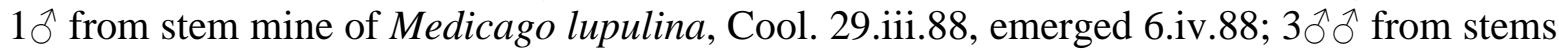

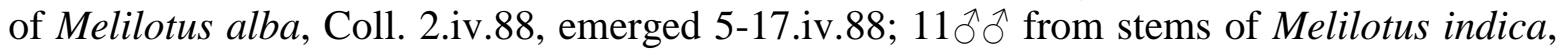

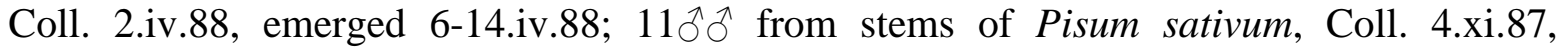
emerged 13-19, 14.xi.87, emerged 15-27; 1 个 same host, Coll. 26.xi,87, emerged 28.xi.87;

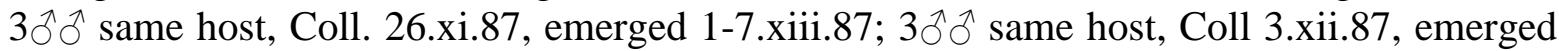
11-27.xii.87; $2 \hat{\jmath} \widehat{\jmath}$ same host, Coll. 3.xii.87, emerged 2-15.xii.87; $2 \hat{\jmath} \widehat{\jmath}$ same host, Coll.

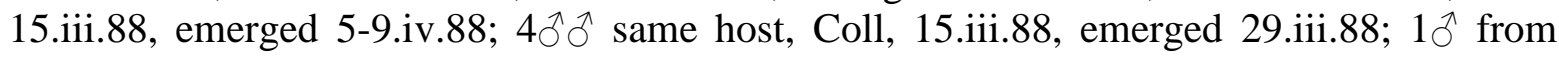
stem of Sesbania aculeate 26.ix.87, emerged 8.x.87; $3{ }^{\lambda} \sigma^{\lambda}$ from stems of Trifolium alexandrium, Coll. 26.iii.87, emerged 1-7.iv.88; $2 \hat{\jmath}$ ô from stems of Trifolium repens, Coll.

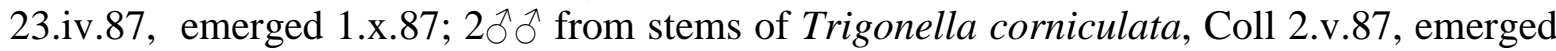
7-9.v.87; $1 \delta^{\Uparrow}$ same host. Coll. 10.v.87, emerged 14.v.87; $1 \delta^{\Uparrow}$ same host, Coll. 30.xi.87, emerged 8.xii.87; 18 $\widehat{\partial}$ same host, Coll. 26.iii.88, emerged 4-7.iv.88; $1 \hat{\jmath}$ from stem of Trigonella foenum-graecum, Coll. 26.iii.88, emerged 30.iii.88; 9ðへへ same host, Coll. 26.iii.88, emerged 3-13.iv.88; $1{ }^{\widehat{ }}$ from stem of Vigna mungo, Coll. 2.x.87, emerged 12.x.87; 


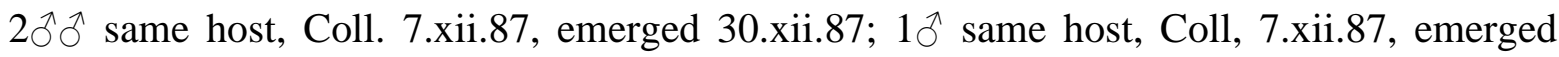
10.i.88; 2 ऊิ same host, Coll 5.i.88, emerged 10.i.88; 1 त from stem mine of Vigna radiata, Coll. 17.x.87, emerged 19.x.87; $1 \overbrace{}^{\hat{~}}$ same host, Coll, 24.x.87, emerged 26.x.87; 1ठ same

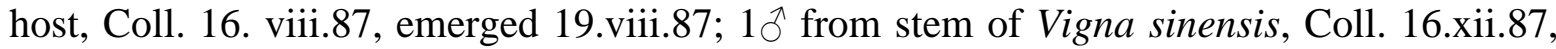
emerged 27.i.88; 10 from stem of $V$. umbellata. Coll. 5.i.88, emerged 25.8.88.

\section{Acknowledgements}

Thanks are due to Dr. P.K. Pathak and Dr. V.K. Sehgal, Professors, Department of Entomology, College of Agriculture, G.B. Pant University of Agriculture and Technology, Nainital, Uttaranchal, India. Further, author is indebted to University Grants Commission, India for providing fellowship to carry this research at that University. Thanks are also due to Dr. Gour and his associates, Forest Research Institute, Dehradun for identification of various host plants.

\section{References}

Poudyal, B. 2003. Species determination and some ecological studies of agromyzid flies associated with some commonly cultivated leguminous crops of Jhapa district, Eastern Nepal. M.Sc. Thesis, Dept. of Zoology, P.G. Campus, T.U., Biratnagar. 87p.

Sasakawa, M. 1960. A study of Japanese Agromyzidae (Diptera). 1, Sci. Rep. Kyoto. Pref, Univ. Agr., 12: 76-82.

Sasakawa, M. 1961. A study of the japanese Agromyzidae (Diptera), 3. Sci.Rep.Kyoto. Pref.Univ. Agr. 13: 60-67.

Sehgal, V.K. 1965. A study on Indian Agromyzidae (Diptera). Beitr. Ent. 15: 3-10.

Sehgal, V.K., M.A. Khan, M. Jyoti, A.K. Sen \& C.K. Mandal. 1980. Survey and taxonomic studies on the Agromyzid flies (Diptera) of north India, with special reference to their host-plant relationships. Rreport of ICAR Adhoc, Research Scheme (1977-1980), G.B. Pant Univ. of Agric. \& Tech., Pantnagar (Nainital), India. 167p.

Spencer, K.A. \& G.C. Steyskal. 1986. Manual of the Agromyzidae (Eiptera) of the United States. U.S.A., U.S. Department of Agriculture, Agriculture hand book No. 638. 478p.

Spencer, K.A. 1973. Agromyzidae (Diptera) of economic importance. Ser. Entomol. 9: 1-405.

Thapa, M. 2005. Study of field population and diversity of Leaf miners (Diptera: Agromyaidae) infesting Mung bean Vigna radiata (Linn.) Wilczek grown in Biratnagar eastern Nepal. M.Sc. Thesis, Dept. of Zoology, Post Graduate Campus, Biratnagar, T.U. Nepal. 226p.

Thapa, R.B. 1991. Survey and taxonomic studies on the Agromyzid flies associated with leguminious hosts at Pantnagar in the northern India. Ph.D. Thesis, G.B. Pant University of Agriculture and Technology, Pantnagar, India. 420p.

Thapa, R.B. 1997. Survey of agromyzid flies (Leaf miners) associated with economically important crops and weed in and around Biratnagar, eastern, Nepal. Report, Research Division, Tribhuvan University, Kirtipur. 15p.

Thapa, R.B. 2000. Survey of agromyzid host range in Morang district, eastern Nepal. Report, UGC, Nepal.

Thapa, R.B. 2011. Description of new species of leaf miners (Diptera, Agromyzidae) associated with leguminous host described from northern India. Nepalese Journal of Biosciences 1: 66-82. 